\title{
QUERCETIN DEGRADATION INDUCED BY CONTINUOUS UV-B IRRADIATION IN THE PRESENCE OF BENZOPHENONE
}

Jelena S. Stanojević1, Dragan J. Cvetković1, Jelena B. Zvezdanović1, Ljiljana P. Stanojević ${ }^{1}$, Milorad D. Cakić ${ }^{1}$, Andrija A. Šmelcerović ${ }^{2}$ Dejan Z. Marković $\dagger^{1}$

${ }^{1}$ Faculty of Technology, Leskovac, Serbia

2Department of Chemistry, Faculty of Medicine, Niš, Serbia

The aim of the present study was to consider quercetin and benzophenone mutual interaction in methanol solution under continuous UV-B irradiation. Following the UV-B induced changes by HPLC chromatography, the obtained results revealed significant acceleration of quercetin degradation in the presence of benzophenone. An unambiguous identification of quercetin degradation products was enabled by direct FI-ESI-MS analysis. The presence of benzophenone did not just accelerate but also changed the mechanism of quercetin degradation. Irradiation of quercetin in the absence of benzophenone led to the formation of the solvent-addition product 2-(3,4-dihydroxyphenyl)-3,5,7-trihydroxy-2,3-dimetoxy-2,3-dihydro-4H-chromen4 -one. The products obtained in the presence of benzophenone, formed as the result of C-ring opening, were identified as 3,5-dihydroxy-2-[methoxy(oxo)acetyl]phenyl 3,4-dihydroxybenzoate and methyl-oxo(2,4,6-trihydroxyphenyl)acetate.
(ORIGINAL SCIENTIFIC PAPER) UDC 547.972.3+547.572:543.42

Keywords: Quercetin, Benzophenone, UV irradiation, HPLC, FI-ESI-MS

\section{Introduction}

The occurrence of different disorders related to prolonged exposure to sunlight, especially to ultraviolet (UV) radiation $(\lambda=100-400 \mathrm{~nm})$, has increased alarmingly in the last few decades. Moreover, recent ozone layer depletion findings are disturbing due to possible consequences of intensified UV-B radiation $(\lambda=280-320 \mathrm{~nm})$ [1]. Although UV-B light participation is $4-5 \%$ in total UV light spectrum, rays from this part are known as "burning rays" exhibiting their effects in epidermal skin layer leading to darkening of the skin, but also to erythema, sunburns, inflammation, direct DNA damage, local and systematic immunosuppression. Those changes could be directly or indirectly included in the skin cancer development [2].

A precondition of photochemical reactions initiated by UV-B radiation in the skin is its absorption by molecules located in the epidermis. Consequently, these molecules excite from ground to higher energy (excited) states. If excited molecules do not relax to the ground state through series of concurrent intramolecular deactivation processes but react with adjacent molecules, then it is the photosensitization process. Therefore, photosensitized reactions require a sufficiently long life of excited states. Compared to singlet excited states, excited triplet states live longer and these reactions usually took place from excited triplets $[3,4]$. Under aerobic conditions (so-called photosensitized oxidations), these reactions occur through two competitive mechanisms designated as Type I and Type II mechanisms. According to Foote [5], Type I mechanism is related to a direct reaction of the excited triplet sensitizer with substrate (such as fatty acids, phenolic compounds etc.) and leads to the free radicals production. The formed radicals react with molecular oxygen giving oxidation products [5].
Benzophenone (BZP - Fig.1b) is typical Type I photosensitizer. Upon light absorption it excites to the first singlet state ( $\left.{ }^{1} \mathrm{BZP}\right)$ and then, by non-radiative intersystem crossing, very efficiently (with quantum yield, $\Phi_{I S C}=1$ ) populates its triplet state ( $\left.{ }^{3} \mathrm{BZP}\right)[6]$. BZP triplet is very reactive toward its surrounding (e.g. lipids - it is not just effective but also very selective toward doubly allylic $\mathrm{H}$-atoms in lipids, thus initiating lipid peroxidation [7-10]).<smiles>Cc1c(O)cc(O)cc1OC(=C(O)C(=O)O)c1ccc(O)c(O)c1</smiles>

(a)<smiles>O=C(c1ccccc1)c1ccccc1</smiles>

(b)
Figure 1. Structures of quercetin (a) and benzophenone (b)

Formerly BZP was the unavoidable component of sunscreens. Since it was characterized as "the most powerful generator of free radicals known to mankind", its use was expelled in Europe. Nevertheless, some of its derivatives are still in use because of wide UV absorption spectrum (200-350 nm) [11]. Since filters based on BZP easier penetrate skin and accumulate in the tissues, as well as in blood, their potential toxicity to humans and ecosystem attracts a lot of attention [12].

Although free radicals were considered harmful at the

\footnotetext{
* Author address: Jelena Stanojević, Faculty of Technology, Bulevar Oslobođenja 124, 16000 Leskovac, Serbia

E-mail: jelena_stanojevic@yahoo.com

The manuscript received: March, 07,2017.

Paper accepted: March, 21,2017
} 
beginning, it was found lately that they play very important roles in normal organism functioning. However, their high concentrations could damage vital biomolecules (proteins carbohydrates, nucleic acids and lipids) thus disturbing the functioning of cells, tissues and whole organism. All living things are endowed with defense arsenal from free radicals in the form of antioxidants. These are substances that, when present in a small concentration prevent or retard the oxidation of biological "targets" neutralizing free radicals [13]. According to their origin, antioxidants could be divided into natural (enzymatic and non-enzymatic) and synthetic. So far, 10000 flavonoid structures are identified making them the most important and most interesting class of plant polyphenols [14].

Quercetin ( $Q C$ ) is a representative of flavonoid's subgroup flavonols (Fig.1a). As the most widespread of all flavonoids, it can be found in fruits and vegetables, tea, red vine, olive oil and propolis [1]. Many studies demonstrated its antioxidant, anticancerogenic, antivirus, antithrombotic, antiishemic, anti-inflammatory and anti-allergic action, as well as the protection from heart diseases and immunity stimulation. Most of the actions listed actually rely on its ability to effectively scavenge ROS species such as superoxide anion radicals, singlet oxygen and hydroxyl radicals, cyclooxygenases and lipoxygenases inhibition and transient metal ions chelation $[15,16]$.

The exact mechanism of the QC antioxidant action is still unknown. According to its absorption spectra characterized by two main bands, designated as Band I (with absorption maxima in the range $\lambda_{\max }=320-385 \mathrm{~nm}$, depending on the solvent used) and Band II ( $\left.\lambda_{\max }=250-280 \mathrm{~nm}\right)$, it absorbs UV radiation with absorption maxima in UV-A ( $\lambda_{\max }=320$ $400 \mathrm{~nm})$ and UV-C $\left(\lambda_{\max }=200-280 \mathrm{~nm}\right)$ portions of UV light reaching the Earth surface. This could be ascribed to the "preventive side"of its antioxidant activity. QC dissipates the absorbed energy as heat, light or by decomposing into its degradation products both in vitro and in vivo $[17,18]$.

So far, many oxidation products of $\mathrm{QC}$ have been isolated and identified. Only Zhou and Sadik [19] identified 22 of them. Namely, QC was oxidized by UV radiation [18,20,21], gamma rays [22], electrochemically [23,24] and enzymatically $[25,26]$; by atmospheric oxygen (autooxidation) [27], DPPH radicals [28] etc., in water, alcoholic, buffered solutions, as well as in organic solvents. Identified degradation products belong to depsides, phenolic acids, (homo- and hetero-) dimers and solvent-addition products.

QC's ability to absorb UV radiation makes photosensitivity studies of special interest in its protective activity evaluation. The experiments performed in solutions are essential because of the elimination of influence from the structural organization giving basic data for further work in more complex media such as micelles, liposomes and finally in vivo. So, UV-B irradiation of QC and BZP mixture was chosen as a model of oxidation reactions that potentially occur in vivo. The alcohol solution was chosen because of QC and BZP insolubility in water.

The other possible mechanism of QC's antioxidant action is scavenging of free radical species - preventing chain reactions such as lipid peroxidation. Those two mechanisms do not exclude each other, just the opposite; they probably act synergistically.

In our previous papers [29,30], QC antioxidant ability in BZP-sensitized lipid peroxidation in methanol solution un- der continuous UV-B irradiation by spectrophotometric [29] and HPLC method was tested [30]. The results showed that the QC antioxidant activity was significantly decreased under the above mentioned conditions. Based on the results obtained by HPLC [30], which provide the separation of involved species, the assumption is that the decreased antioxidant activity could be related to BZP-QC mutual interaction. Therefore, the main objective of this paper is further examination of the mentioned interaction so the observed phenomena can be explained.

\section{Experimental}

\section{Sample preparation}

Stock solutions of QC and BZP were prepared by dissolving $10 \mathrm{mg}$ of QC i.e. $25 \mathrm{mg}$ of BZP (Sigma Aldrich Co., St. Louis, MO, USA) in $25 \mathrm{~cm}^{3}$ of methanol (Ultra Gradient HPLC Grade; J.T. Baker, Deventer, The Netherlands). Working solutions were made freshly, by diluting the stocks, and stored at $4{ }^{\circ} \mathrm{C}$ until their use, protected from light with aluminium foil (to avoid any photochemical changes). HPLC analysis was performed with the methanol solution of BZP (c = $\left.1 \times 10^{-4} \mathrm{moldm}^{-3}\right)$ and QC $\left(\mathrm{c}=5 \times 10^{-5} \mathrm{moldm}^{-3}\right)$. $\mathrm{FI}-\mathrm{ESI}-\mathrm{MS}$ analysis was performed with the methanol solution of QC and BZP (both in the concentration of $\mathrm{c}=5 \mathrm{mg}$ $\mathrm{dm}^{-3}$ ). All experiments were done at room temperature. The $\mathrm{pH}$ value of the samples was 7.1.

\section{UV-Irradiation}

Continuous irradiations of samples in methanol, in aliquots of $2.5 \mathrm{~cm}^{3}$ were performed in a cylindrical photochemical reactor "Rayonet", with 10 symmetrically placed lamps with the emission maximum at $300 \mathrm{~nm}$ (UV-B). The samples were irradiated in quartz closed cuvettes $(1 \times 1 \times$ $4.5 \mathrm{~cm}$ ) placed on a rotating circular holder. The total measured energy flux was $15.0 \mathrm{Wm}^{-2}$ at $10 \mathrm{~cm}$ distance from the lamps.

\section{HPLC chromatography}

The irradiated samples were filtered through $0.45 \mu \mathrm{m}$ filter (Thermo Scientific, Germany) and immediately analyzed with the Agilent 1100 Series system (Waldbron, Germany), equipped with a binary pump (Agilent 1100 Series), autosampler (Agilent 1200 Series) and DAD detector (Agilent 1200 Series, the wavelength range $190-800 \mathrm{~nm}$ ) injecting $20 \mu \mathrm{L}$ into the mobile phase under flow of $1.0 \mathrm{~cm}^{3} \mathrm{~min}^{-1}$. The mobile phase consisted of $35 \% \mathrm{~A}$ (formic acid, $0.1 \%$ water solution) and $65 \% \mathrm{~B}$ (formic acid, $0.1 \%$ methanol solution). The samples were separated into individual components on Zorbax Eclipse Plus C18 column $(4.6 \times 250 \mathrm{~mm}$, $5 \mu \mathrm{m})$, thermostated at $25^{\circ} \mathrm{C}$ using the isocratic regime of elution. According to the order of their elution, all separated components arrived to DAD detector tuned in wavelengths of $\lambda_{\text {det }}=250 \mathrm{~nm}$ (detection wavelength for BZP), $\lambda_{\max }=295$ $\mathrm{nm}$ (absorption maximum of possible QC decomposition products) and $\lambda_{\max }=371 \mathrm{~nm}$ (absorption maximum of QC). Solutions of pure QC and BZP were irradiated separately one by one, as a kind of blank, and analyzed simultaneously with the QC-BZP mixture.

Direct flow injection-electrospray mass spectrometry (FI-ESI-MS)

Non-irradiated and UV-B irradiated samples of QC and 
QC-BZP mixture were pumped by a syringe pump (volume $500 \mu \mathrm{l}$, Hamilton Co., Reno, Nevada, USA) under the flow of $50 \mu \mathrm{min}^{-1}$ directly into an ion source. The MS-analysis was performed using a LCQ 3D-ion trap mass spectrometer (LCQ Fleet Ion Trap Mass Spectrometer, Thermo Fisher Scientific, the USA) with electrospray ionization (ESI) in a negative ion mode. The ESI(-) source parameters were set as follows: source voltage $4.95 \mathrm{kV}$, capillary voltage $-50 \mathrm{~V}$, tube lens voltage $-124,96 \mathrm{~V}$, capillary temperature $275^{\circ} \mathrm{C}$, and depending on the sample nature: sheath and the auxiliary gas flow $\left(\mathrm{N}_{2}\right) 20$ au and 30 au i.e. 2 au and 5 au (arbitrary units), respectively. MS spectra were obtained by the full range acquisition of $\mathrm{m} / \mathrm{z}=95-1000$. For the fragmentation study (MS/MS), a data dependent scan was performed by deploying the collision-induced dissociation (CID). The normalized collision energy of the CID cell was set in the range of $15-30 \mathrm{eV}$.

\section{Results and Discussion}

UV-B induced bleaching of QC in QC-BZP mixture

The UV-B induced changes i.e. the degradation (bleaching) of QC and BZP in the QC-BZP mixture as a result of the increased UV-B irradiation periods is shown in Figure 2. Since the UV-B radiation could exert its effects on both components present in the studied mixture, antioxidant (QC) and sensitizer (BZP) were irradiated separately as a kind of blank. Their kinetic plots, together with those in the QC-BZP mixture, are shown in Figure 2c1 and 2c2, respectively.

QC's (in)stability was studied in different media, under different experimental (stressful) conditions. Due to the presence of numerous hydroxyl groups in its structure (Fig.1a), low pKa values and high redox potential, it is highly susceptible to oxidation [31].
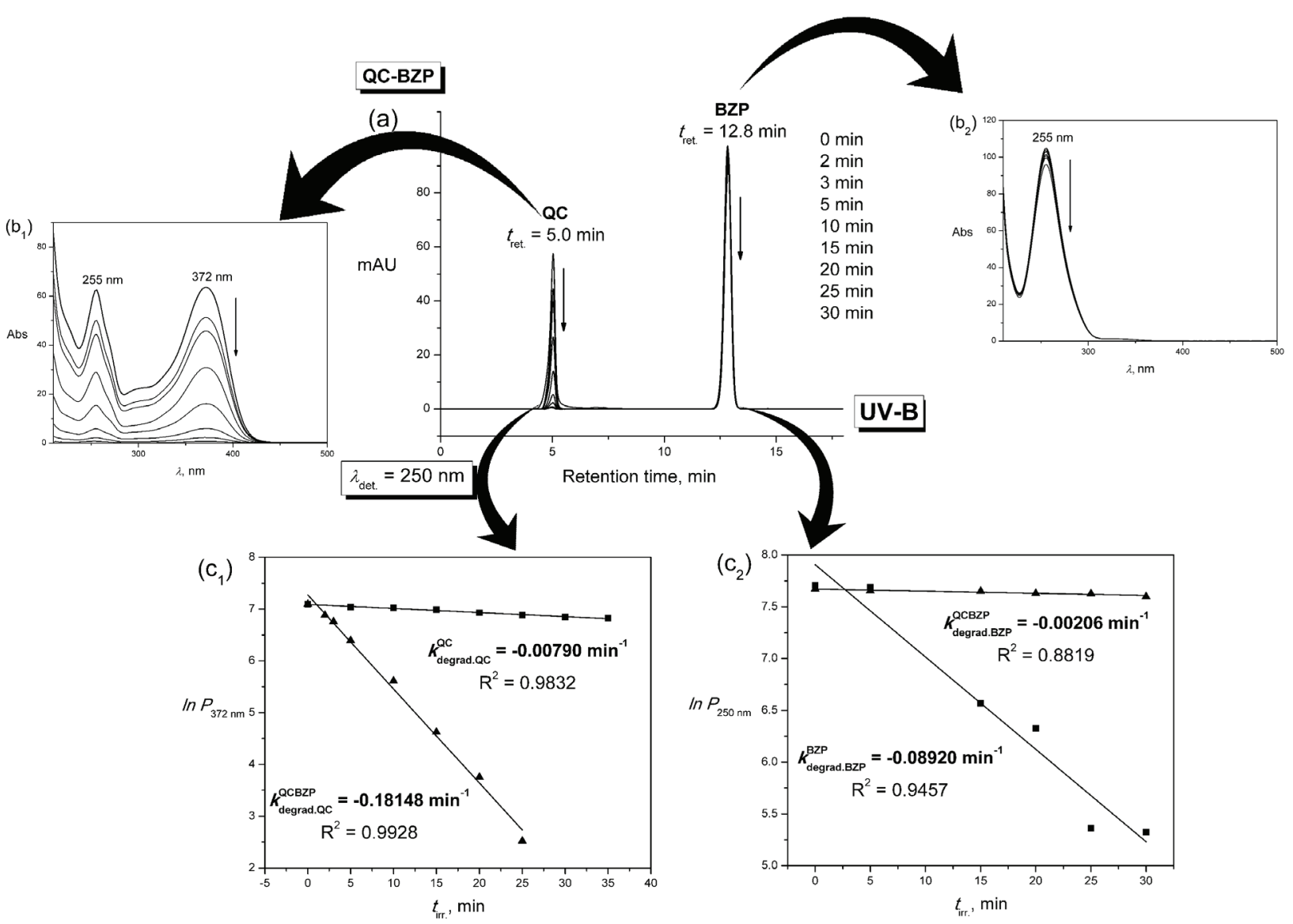

Figure 2. QC-BZP mixture in methanol. (a) Chromatograms of non-irradiated and UV-B irradiated QC-BZP mixture, recorded at the wavelength close to BZP absorption maximum $\left(\lambda_{\text {det }}=250 \mathrm{~nm}\right)$. Retention times of QC and BZP are 5.0 min and 12.8 min, respectively. (b) Changes of $Q C\left(b_{1}\right)$ and BZP $\left(b_{2}\right)$ absorption spectra obtained from the chromatograms recorded at $372 \mathrm{~nm}$ (QC) and $250 \mathrm{~nm}$ (BZP), respectively, with the increase of continuous UV-B irradiation time (tirr). (c) Kinetics of UV-B induced bleaching of QC $\left(\mathrm{C}_{1}\right)$ and BZP $\left(\mathrm{C}_{2}\right)$, followed by the decrease of their peak areas from chromatograms recorded at $372 \mathrm{~nm}$ and $250 \mathrm{~nm}$, respectively as a function of UV-B irradiation time $-\ln P_{372}=\mathrm{f}$ (tirr) and $\ln P_{250}=\mathrm{f}$ (tirr). The corresponding bleaching rate constants obtained during irradiation of QC and BZP individually ( $k_{\text {degrad.QC }}^{\text {QC }}$ and $k_{\text {degrad.BZP })}^{\text {BZP }}$ and in the QC-BZP mixture ( $k_{\text {degrad.QC }}^{\text {QC-BZP }}$ and $k_{\text {degrad.BZP }}^{\text {QC-BZP }}$ ) and coefficients of determination are also given. 
Chromatograms of non-irradiated and UV-B irradiated mixture, recorded at $\lambda_{\text {det }}=250 \mathrm{~nm}$, reveal two peaks, eluted at retention times of $5.0 \mathrm{~min}$ and $12.8 \mathrm{~min}$, identified (on the basis of their absorption (UV) spectra shown in Fig. 2b1 and 2b2) as QC and BZP, respectively. Prolonged continuous UV-B irradiation caused a gradual decrease of their integrated peak areas (concentration) with increasing the time of irradiation (tirr.) - denoted by arrows directed down next to the corresponding peaks on chromatograms. The corresponding kinetic plots (shown in Fig.2c1 and 2c2) followed the observed degradation pattern. According to the first order degradation rate constants, obtained as slopes from the corresponding linear kinetic plots, BZP increases QC degradation 23 times $\left(k_{\text {degrad.QC }}^{\text {QCBZP }} / k_{\text {degrad.QC }}^{Q C C}=-0.18148 /-0.00790\right.$ ). On the other side, the QC's preventive effect is obvious. Namely, the degradation of BZP in the QC-BZP mixture is 43 times slower $\left(k_{\text {degrad.BZP }}^{\text {BZP }} / k_{\text {degrad.BZP }}^{\text {BZP_QC }}=-0.08920 /-0.00206\right)-$ see Fig.2c1 and C2. In other words, during 35 minutes of UV-B irradiation QC degrades up to $23 \%$ (the measure of its preventive action), but in the presence of BZP this percent reaches enormous $99 \%$ during 25 minutes of irradiation.

The obtained results confirm the observations by Fahlman and Krol [18] obtained under similar experimental conditions. Since BZP is a typical Type I sensitizer that produces free radicals (ROS species among them, especially superoxide anion radicals), the observed phenomena is expected. So, the remaining $76 \%$ could be roughly ascribed to the QC scavenging activity.

In our recent publication [29], UV (-A, -B and -C) induced degradation of $\mathrm{QC}$ and the change of its antioxidant activity in the presence of two different phospholipid mixtures (PL80 and PL90) in methanol, in the presence and in the absence of BZP was studied. BZP accelerated QC degradation 3 times thus lowering its antioxidant activity in UV-irradiated mixtures with phospholipids. Considering the objective limitations of UV-VIS spectrophotometry to study complex mixtures such as the mentioned one (QC-BZPPL80/PL90) because of obvious overlapping of absorption spectra from individual components $\left(\lambda_{\max }=255\right.$ and 372 $\mathrm{nm}$ for QC; $250 \mathrm{~nm}$ for BZP and $234 \mathrm{~nm}$ for conjugated dienes), it was impossible to come to deeper conclusions [29]. Therefore, we had to use a new approach in studding the mentioned mixture, first of all by changing the whole method.

Thus, UV-B induced changes of the QC-BZP-PL90 mixture studied by HPLC chromatography allowed a kinetic analysis of clearly separated species [30]. Isocratic elution of the mixture with methanol as a mobile phase gave chromatograms recorded at absorption maxima of the separated components: QC, tret. $=2.6$ min at $371 \mathrm{~nm}$; BZP, tret. $=3.3 \mathrm{~min}$ at $\lambda_{\text {det }}=250 \mathrm{~nm}$; non oxidized lipids, $\mathrm{NL}-$ tret. $=10.1 \mathrm{~min}$; $12.2 \mathrm{~min}$ and $15.5 \mathrm{~min}$ at $210 \mathrm{~nm}$; and conjugated dienes designated as Per1 - tret. $=5.5 \mathrm{~min}$ and Per2 tret. $=6.5 \mathrm{~min}$ at $234 \mathrm{~nm}$. Kinetic data obtained by integrating peak areas from the corresponding chromatograms represented are in some way "purer" in comparison to the "mixed" behavior in the previous paper [29].

The statement primarily refers to the fact that it was impossible to follow the kinetics of BZP degradation by using a spectrophotometric method in the simultaneous presence of $\mathrm{QC}$ due to the complete overlap of its absorption maximum $\left(\lambda_{\max }=252 \mathrm{~nm}\right)$ with Band II $\left(\lambda_{\max }=255 \mathrm{~nm}\right)$ of QC. A new approach allowed uninterrupted following of BZP degradation kinetics, but brought a new problem reflected in disabling of "pure" QC degradation kinetics following. Namely, the absorption spectra of QC (tret. = $2.6 \mathrm{~min}$ ) obtained from the chromatograms recorded at absorption maximum of its Band I $\left(\lambda_{\max }=372 \mathrm{~nm}\right)$ exhibit a drastic change during irradiation time in comparison to the nonirradiated one - with absorbance maxima at $\lambda \max =372$ and $\lambda_{\max }=255 \mathrm{~nm}$. Actually, the absorbance of previous bands has decreased, while absorbance of the band in the wavelength range $\lambda=273-322 \mathrm{~nm}$ has simultaneously increased during the irradiation time. The spectra have also shown a blue shift of Band I (originated from the conjugated B-C system) and a red shift of Band II (from A-C conjugated system) indicating the conjugated system shortening. Also, two isosbestic points at $\lambda=273 \mathrm{~nm}$ and $\lambda=322 \mathrm{~nm}$ indicate the formation of at least one degradation product. By comparing $Q C$ degradation rates in the absence (QC-PL90) and in the presence of BZP (QC-BZP-PL90), it was evident that BZP accelerates QC degradation up to 10 times [30]. It was concluded that suppression of $Q C$ antioxidant activity on one side, and the inhibition of BZP sensitizing activity on the other is somehow related to $\mathrm{BZP}\left({ }^{3} \mathrm{BZP}\right)-\mathrm{QC}$ mutual interaction.

This paper improves findings about the QC-BZP-PL90 mixture in the way that it actually focuses on QC-BZP interaction by changing the chromatographic method. Namely, the change of the mobile phase composition by adding water up to $35 \%$ allowed undisturbed monitoring of QC "alone“ degradation (separated from its degradation products).

Following the UV-B induced photodegradation of QC, signal at $\lambda_{\max }=295 \mathrm{~nm}$ (absorption maximum of potential QC degradation products - designated as QCDP) revealed a dominant peak at $3.6 \mathrm{~min}$. Its UV spectra was characterized by only one band with absorption maximum at $\lambda_{\max }=$ 293 nm (designated as QCDP1) (data not shown). Irradiation of QC-BZP mixture resulted in the appearance of at least three new peaks, eluted at $3.4 \mathrm{~min}, 3.7 \mathrm{~min}$ and 4.4 min with the later two $(\mathrm{QCDP} 2$, tret. $=4.4 \mathrm{~min}$; $\mathrm{QCDP} 3$, tret. $=$ $3.7 \mathrm{~min}$ ) as dominant ones indicating a different mechanism of QC degradation in the absence and in the presence of BZP (data not shown). Absorption spectra of QCDP2 contain the absorption maximum at $\lambda_{\max }=298 \mathrm{~nm}$ and a shoulder at $\lambda_{\max }=274 \mathrm{~nm}$ while spectra of QCDP2 possess only one band, at $\lambda_{\max }=299 \mathrm{~nm}$. QC degradation products with almost the same spectral characteristics have been noticed in our recent publication [32]. Photodegradation of QC in methanol and rutin in methanol and water under continuous UV-B and UV-C irradiation by UV-VIS spectrophotometry and HPLC chromatography was also observed. The chromatograms obtained revealed four QC's (three of them were observed in this paper - QCDP1-3) and two rutin degradation products. According to the similarity of their spectral characteristics with those available in the literature, possible structures were suggested. Therefore, the structure of 2,4,6-trihydroxy-phenylglyoxylic acid [26] was ascribed to the product characterized by absorption maximum at $\lambda_{\max }$ = $294 \mathrm{~nm}$ (similar to QCDP1 observed in this paper). The structure proposed for the product with absorption maximum at $\lambda_{\max }=300 \mathrm{~nm}$ (similar to QCDP3 in this paper) corresponds to 1,3,8-trihydroxy-9aH,11H-benzofuro[3,2-b]-[1] benzopyran-7,11-dione [27]. Both structures correspond to 
the products observed during electrochemical oxidation of QC. For the product observed during gamma irradiation of QC in methanol with the absorption maximum at $\lambda_{\max }=297$ $\mathrm{nm}$ and a shoulder at $\lambda_{\max }=275 \mathrm{~nm}$ the name 3,5-dihydroxy-2-[methoxy(oxo)acetyl]phenyl 3,4-dihydroxybenzoate was proposed [22]. Obviously, none of the products the spectra of which were compared to the spectra observed in [32] was formed as a consequence of UV irradiation of QC.

Therefore, the aim of the pilot experiment with electrospray ionization-mass spectrometry analysis of non-irradiated and UV-B irradiated solution of QC and BZP-QC mixture in methanol was the unambiguous identification of QC's UV-B photodegradation products formed.
Identification of QC degradation products by FI-ESI-MS technique

Mass spectra in a full scan mode obtained by a direct FI-ESI-MS method revealing basic ions from non-irradiated and UV-B irradiated QC in the absence and in the presence of BZP are shown in Figure 3a-C, respectively. Mass spectra of non-irradiated QC (Fig.3a) and QC-BZP mixture (data not shown) reveal two peaks. The first one, at $\mathrm{m} / \mathrm{z}$ 301.08 belongs to QC molecular ion (deprotonated molecule) $[\mathrm{M}-\mathrm{H}]^{-}$while the other one, at $\mathrm{m} / \mathrm{z} 602.58$ originates from QC dimer representing a frequent problem in interpretation of the results obtained by soft ionization techniques because the tendency of dimer formation increases with the increases of the analytes concentration [33].

Relative intensities of the peaks observed at $m / z 331$ and $m / z 363$ in ESI(-) mass spectra of QC increased with the increases of irradiation time with the simultaneous decrease of QC peak (m/z 301) intensity - Fig.3a and 3b.

(a)

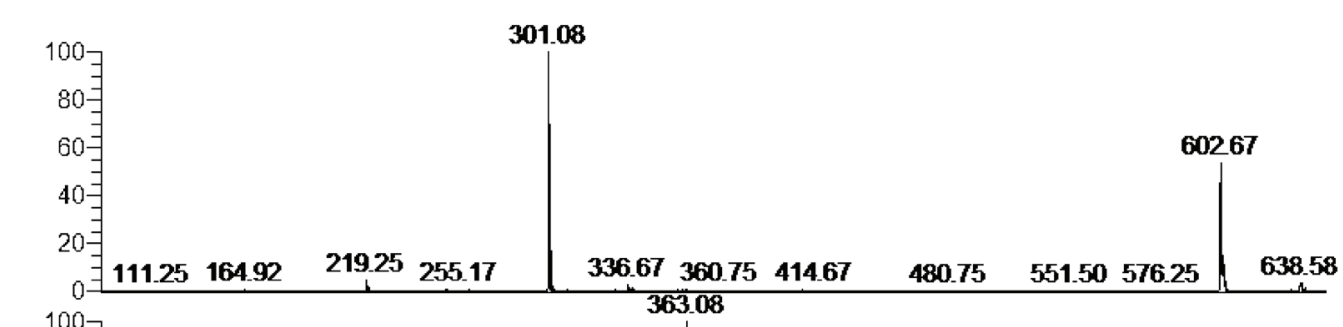

(b)

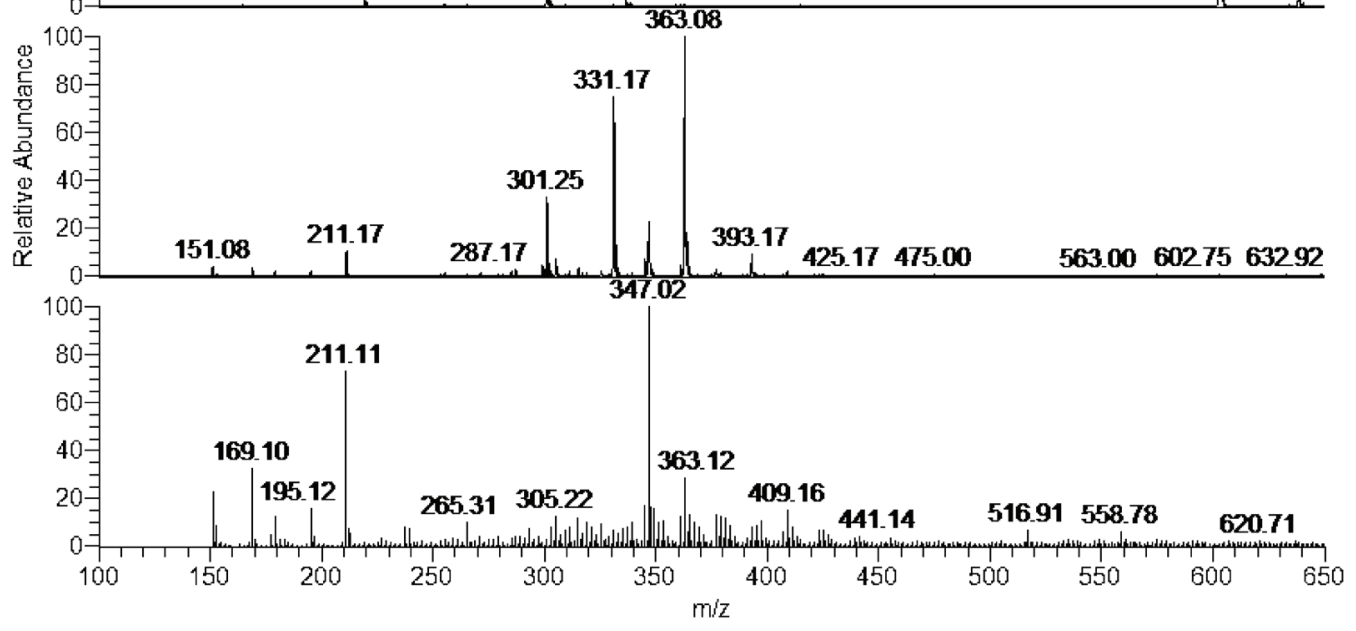

NL- 4.7TE2

quercetin standard full117 RT: $0.00-0.05$ AV: 17 T: IMSS-p ESI Ful ms [100.00-1000.00]
NL- $9.29 \mathrm{E} 3$

quercetin unb60 futh1-18 RT: $0.00 \overline{0} 05 \overline{\mathrm{AV}}: 18 \mathrm{~T}$ ITMS - p ESI Ful ms [100-00-1000-00]

\section{NL- $9.82 \mathrm{E} 2$ qbe-ub60 min fullt1-6 RT: $0.00-0.05$ AV $: 6$ T: IIMS - c ESI Ful ms [150-00-1000.00]}

Figure 3. A comparative view of full scan ESI-MS spectra of (a) non-irradiated (b) UV-B 60 min irradiated QC in methanol and (c) UV-B 60 min irradiated QC-BZP mixture in methanol, recorded in the negative ionization mode.

Base peak in ESI(-) mass spectrum of the UV-B irradiated BZP-QC mixture after tirr $=60 \mathrm{~min}$ is at $\mathrm{m} / \mathrm{z} 347$ (Fig.3c). Relative peak intensity at $\mathrm{m} / \mathrm{z} 211$ increased with the increases of UV-B irradiation time with the simultaneous decrease of the QC peak intensity (Fig.3C). The molecular peak of $Q C$ is absent after 60 min of UV-B irradiation of the QC-BZP mixture (Fig.3C), thus confirming the results obtained by HPLC analysis - that BZP accelerates $\mathrm{QC}$ degradation. The obtained results also confirm the conclusion based on the monitored chromatograms - that the mechanism of QC degradation in the presence and in the absence of BZP is different.

All mentioned ions were selected as precursors for further fragmentation. $\mathrm{MS}^{2}$ and $\mathrm{MS}^{3}$ spectra of the main QC degradation products were obtained by fragmenta- tion of chosen parent ions with the appropriate collision energy. Since $Q C$ fragmentation is very well known, it was easy to ascribe the observed ions to the corresponding fragments. Therefore, collision energy of $25 \mathrm{eV}$ applied to QC molecular ion [M-H]- $(\mathrm{m} / \mathrm{z} 301)$ gave the following fragmentation ions: $[\mathrm{M}-\mathrm{H}-\mathrm{CO}]^{-}$at $\mathrm{m} / \mathrm{z} 273$; $\left[\mathrm{M}-\mathrm{H}-\mathrm{CO}_{2}\right]^{-}$at $\mathrm{m} / \mathrm{z}$ 257; [M-H- $\left.\mathrm{C}_{7} \mathrm{H}_{6} \mathrm{O}_{2}\right]^{-}$at $\mathrm{m} / \mathrm{z}$ 179; [M-H- $\left.\mathrm{C}_{7} \mathrm{H}_{6} \mathrm{O}_{2}-\mathrm{CO}\right]^{-}$ at $\mathrm{m} / \mathrm{z} 151$ and $\left[\mathrm{M}-\mathrm{H}-\mathrm{C}_{7} \mathrm{H}_{6} \mathrm{O}_{2}-\mathrm{CO}-\mathrm{CO}_{2}\right]^{-}$at $\mathrm{m} / \mathrm{z} 107$.

By applying collision energy (CID) of $15 \mathrm{eV}$ to an ion at $\mathrm{m} / \mathrm{z} 363, \mathrm{MS}^{2}$ spectrum with the base peak at $\mathrm{m} / \mathrm{z} 331$ was obtained. Further fragmentation (using CID energy of $21 \mathrm{eV}$ ) gave $\mathrm{MS}^{3}$ spectrum with the base peak at $\mathrm{m} / \mathrm{z}$ 299. An ion at $m / z 363$ corresponds to $Q C$ with two solvent molecules (methanol) added. The confirmation of the proposed structure is in the fragmentation pattern 
observed - the reduction of the basic peak mass for 32 $\mathrm{Da}$ (loosing of $\mathrm{CH}_{3} \mathrm{OH}$ molecule) followed by loosing of the second metoxy group in metoxy radical releasing (mass reduction for $31 \mathrm{Da}$ ) - the appearance of the fragment ion at $\mathrm{m} / \mathrm{z} 300.08$; or methanol releasing (mass reduction for $32 \mathrm{Da}$ ) - the appearance of the fragment ion at $m / z 299$.

According to spectral characteristics and fragmentation patterns, the proposed structures for observed QC degradation products are shown in Figure 4. The identical fragmentation scheme was observed for the $\mathrm{QC}$ oxidation product formed in the reaction of $\mathrm{QC}$ with DPPH radical in methanol [28]. Moreover, its spectral characteristics (having only one band with absorption maximum at $295 \mathrm{~nm}$ ) are almost identical to QCDP1 observed in this paper. The product was identified as 2-(3,4-dihydroxyphenyl)-3,5,7-trihydroxy-2,3-dimetoxy-2,3dihydro-4H-chromen-4-one [28] - Fig.4.

Molecular ion [M-H] ${ }^{-}$at $\mathrm{m} / \mathrm{z} 347$ (Fig.3c) was observed in LC-ESI(-)-MS spectra obtained during radiolysis of QC in methanol [22]. This compound, identified as 3,5-dihydroxy-2-[methoxy(oxo)acetyl]phenyl 3,4-dihydroxybenzoate, possesses spectral characteristics very similar to the QCDP2 observed in this paper - absorption maximum at $\lambda_{\max }=298 \mathrm{~nm}$ and a shoulder at $\lambda_{\max }$ $=275 \mathrm{~nm}$. Finally, the compound observed as an ion at $\mathrm{m} / \mathrm{z} 211$ (QCDP3) was identified as methyl-oxo(2,4,6trihydroxyphenyl)acetate [22] (Fig.4).<smiles>COC(=O)C(=O)c1c(O)cc(O)cc1OC(=O)c1ccc(O)c(OC(=O)c2cc(O)cc(O)c2C(=O)C(=O)OC)c1</smiles>

Figure 4. Proposed structures of main $Q C$ degradation products formed during continuous UV-B irradiation of QC in the absence (QCDP1) and in the presence of BZP (QCDP2 and QCDP3).

\section{Conclusion}

The results obtained in this paper confirm the results previously observed by UV-VIS spectrophotometry and HPLC chromatography analysis of the BZP-QC-PL90 mixture (considering faster degradation of $Q C$ in the presence of BZP). Although the ratio of $\mathrm{QC}$ degradation rate constants in the presence and in the absence of BZP is higher - 24 vs 3 (UV-VIS spectrophotometry) and 10 (HPLC chromatography), having in mind the objective limitations of UV-VIS spectrophotometry, as well as isocratic HPLC elution, these results are even more accurate. The FI-ESI-MS technique identifies UV-B induced degradation products of $\mathrm{QC}$. In the absence of BZP, QC degrades giving a solvent-addition product identified as 2-(3,4-dihydroxyphenyl)-3,5,7-trihydroxy-2,3-dimetoxy-2,3dihydro-4H-chromen-4-one. The presence of BZP significantly accelerates QC degradation simultaneously changing the mechanism of its degradation. $Q C$ degradation products formed during UV-B irradiation of the
QC-BZP mixture, as a consequence of C-ring opening, are identified as 3,5-dihydroxy-2-[methoxy(oxo)acetyl] phenyl 3,4-dihydroxybenzoate and methyl-oxo(2,4,6-trihydroxyphenyl)acetate. Since the antioxidant activity of QC depends on the presence of 2,3-double bond conjugated with $3-\mathrm{OH}$ in the C-ring, its opening could be the result of a direct excitation energy transfer from ${ }^{3} \mathrm{BZP}$ to QC consequently lowering its antioxidant activity. Also, the inhibition of BZP sensitizing activity, according to degradation rate constants in the absence and presence of QC, could be ascribed to the quenching of its triplet state by QC.

\section{Acknowledgment}

This work is part of the research project "Plant and synthetic bioactive products of new generation," no. TR 34012, financed by the Ministry of Education, Science and Technological Development of the Republic of Serbia. 


\section{References}

[1] A. Svobodová, J. Psotová, D. Walterová, Natural phenolics in the prevention of UV-induced skin damage. A review, Biomedical Papers of the Medical Faculty of the University Palacky Olomouc Czech Republic, 147(2) (2003) 137 145.

[2] N. Schade, C. Esser, J. Krutmann, Ultraviolet B radiationinduced immunosuppression: molecular mechanisms and cellular alterations, Photochemical and Photobiological Sciences, 4(9) (2005) 699 - 708.

[3] G. T. Wondrak, M. K. Jacobson, E. L. Jacobson, Endogenous UVA-photosensitizers: mediators of skin photodamage and novel targets for skin photoprotection, Photochemical \& Photobiological Sciences, 5(2) (2006) $215-237$.

[4] H. - P. Lassalle, Etude des mécanismes du photoblanchiment de la 5,10,15,20-tetrakis(mhydroxyphenyl)bactériochlorine, en solution, in vitro et in vivo, PhD Thesis, Faculte de medecine, Universite Henri Poincare-Nancy I, 2005.

[5] C.S. Foote, Mechanisms of photosensitized oxidation, Science, 162 (3857) (1968) 963 - 970.

[6] P. Klán, J. Wirz Photochemistry of organic compounds: from concepts to practice, John Wiley \& Sons Ltd., Chichester, 2009, p. 127.

[7] D. Z. Marković, Photochemistry of aromatic ketones in sodium dodecyl sulphate micelles in the presence of unsaturated fatty acids, Journal of Serbian Chemical Society 69(2) (2004) 107 - 115.

[8] D. Z. Marković, T. Durand, L. K. Patterson, Hydrogen abstraction from lipids by triplet states of derivatized benzophenone photosensitizers, Photochemistry and Photobiology, 51(4) (1990) 389 - 394.

[9] D. Z. Marković, L. K. Patterson, Radical processes in lipids. Selectivity of hydrogen abstraction from lipids by benzophenone triplet, Photochemistry and Photobiology, 49(5) (1989) 531 - 535.

[10] D. Z. Marković, L. K. Patterson, Benzophenone-sensitized lipid peroxidation in linoleate micelles, Photochemistry and Photobiology, 58(3) (1993) 329 - 334.

[11] A. Beckett, B. McClure, K. Zimmerman, Benzophenone and padimate-O protect Saccharomyces cerevisiae from UV radiation and cause little harm from UV-induced reactive chemical species, Journal of Experimental Microbiology and Immunology, 5 (2004) 37 - 43.

[12] F. Zhang, J. Zhang, C. Tong, C. Yadong, Z. Shulin, L. Weiping Molecular interactions of benzophenone UV filters with humanserum albumin revealed by spectroscopic techniques and molecular modeling, Journal of Hazardous Materials, 263(Part 2) (2013) 618 - 626.

[13] A. R. Ndhlala, M. Moyo, J. V. Staden, Natural antioxidants: fascinating or mythical biomolecules?, Molecules, 15(10) (2010) 6905 - 6930.

[14] S. Tahara, A journey of twenty-five years through the ecological biochemistry of flavonoids, Bioscience, Biotechnology and Biochemistry, 71(6) (2007) 1387 1404.

[15] A. Saija, A. Tomaino, D. Trombetta, M. L. Pellegrino, B. Tita, C. Messina, F. P. Bonina, C. Rocco, G. Nicolosi, F. Castelli, "In vitro" antioxidant and photoprotective properties and interaction with model membranes of three new quercetin esters, European Journal of Pharmaceutics and Biopharmaceutics, 56(2) (2003) 167 - 174.
[16] U. J. Joshi, A. S. Gadge, P. D’Mello, R. Sinha, S. Srivastava, G. Govil, Anti-inflammatory, antioxidant and anticancer activity of quercetin and its analogues, International Journal of Research in Pharmaceutical and Biomedical Sciences, 2(4) (2011) 1756 - 1766.

[17] E. Falkovskaia, P. K. Sengupta, M. Kasha, Photophysical induction of dual fluorescence of quercetin and related hydroxyflavones upon intermolecular $\mathrm{H}$-bonding to solvent matrix, Chemical Physics Letters, 297(1-2) (1998) 109 - 114.

[18] B. M. Fahlman, E. S. Krol, UVA and UVB radiation-induced oxidation products of quercetin, Journal of Photochemistry and Photobiology B: Biology, 97(3) (2009) 123 - 131.

[19] A. Zhou, O. A. Sadik, Comparative analysis of quercetin oxidation by electrochemical, enzymatic, autoxidation, and free radical generation techniques: a mechanistic study, Journal of Agricultural Food Chemistry, 56(24) (2008) 12081 - 12091.

[20] F. T. M. C. Vicentini, S. R. Georgetti, J. R. Jabor, J. A. Caris, M. V. L. B. Bentley, M. J. V. Fonseca, Photostability of quercetin under exposure to UV irradiation, Latin American Journal of Pharmacy, 26(1) (2007) 119 - 124.

[21] S. Dall'Acqua, G. Miolo, G. Innocenti and S. Caffieri, The photodegradation of quercetin: relation to oxidation, Molecules, 17(8) (2012), 8898 - 8907.

[22] A. Marfak, P. Trouillas, D. P. Allais, C. A. Calliste and J. L. Duroux, Redox reactions obtained by gamma irradiation of quercetin methanol solution are similar to in vivo metabolism, Radiation Research, 159(2) (2003) 218 - 227.

[23] A. Zhou, S. Kikandi, O. A. Sadik, Electrochemical degradation of quercetin: Isolation and structural elucidation of the degradation products, Electrochemistry Communications, 9(9) (2007) 2246 - 2255.

[24] A. K. Timbola, C. D. de Souza, C. Giacomelli, A. Spinelli, Electrochemical oxidation of quercetin in hydro-alcoholic solution, Journal of the Brazilian Chemical Society, 17(1) (2006) 139 - 148.

[25] H. M. Awad, M. G. Boersma, J. Vervoort, I. M. C. M. Rietjens, Peroxidase-catalyzed formation of quercetin quinone methide-glutathione adducts, Archives of Biochemistry and Biophysics, 378(2) (2000) $224-233$.

[26] S. R. Savić, J. S. Stanojević, D. Z. Marković, Ž. B. Petronijević, Quercetin oxidation by horseradish peroxidase: the effect of UV-B irradiation, Hemijska Industrija, 67(3) (2013) 411 - 418.

[27] I. G. Zenkevich, A. Y. Eshchenko, S. V. Makarova, A. G. Vitenberg, Y. G. Dobryakov, V. A. Utsal, Identification of the products of oxidation of quercetin by air oxygen at ambient temperature, Molecules, 12(3) (2007) 654 - 672.

[28] E. Hvattum, Y. Stenstrøm, D. Ekeberg, Study of the reaction products of flavonols with 2,2-diphenyl-1-picrylhydrazyl using liquid chromatography coupled with negative electrospray ionization tandem mass spectrometry, Journal of Mass Spectrometry, 39(12) (2004) 1570 - 1581.

[29] J. B. Zvezdanović, D. Z. Marković, D. J. Cvetković, J. S. Stanojević, UV-induced change in the antioxidant activity of quercetin toward benzophenone-initiated lipid peroxidation, Journal of the Serbian Chemical Society, 77(11) (2012) 1571 - 1588.

[30] J. S. Stanojević, D. Z. Marković, J. B. Zvezdanović, Benzophenone suppression of quercetin antioxidant activity towards lipids under UV-B irradiation regime: detection by HPLC chromatography, Journal of Chemistry, 2013 (2013) 1-9, Article ID 761675. 
[31] B. M. Fahlman, In vitro studies to assess the potential of quercetin as a topical sunscreen; photooxidative properties, photostability and inhibition of UV radiationmediated skin damage, $\mathrm{PhD}$ thesis, College of Pharmacy and Nutrition, University of Saskatchewan, 2010.

[32] J. B. Zvezdanović, J. S. Stanojević, D. Z. Marković and D. J. Cvetković, Irreversible UV-induced quercetin and rutin degradation in solution studied by UV spectrophotometry and HPLC chromatography, Journal of Serbian Chemical Society, 77(3) (2012), 297 - 312.
[33] R. B. Cody, Electrospray ionization mass spectrometry: history, theory, and instrumentation in Applied electrospray mass spectrometry, Eds. B. N. Pramanik, A. K. Ganguly, M. L. Gross, Marcel Dekker, Inc. New York 2002, p. 1.

Izvod

\section{DEGRADACIJA KVERCETINA U PRISUSTVU BENZOFENONA INDUKOVANA KONTINUALNIM UV-B OZRAČIVANJEM}

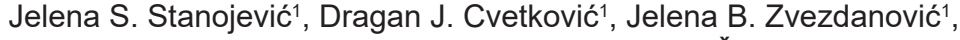

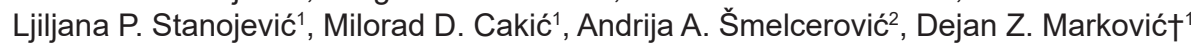

1 Tehnološki fakultet, Leskovac, Srbija

2Departman za hemiju, Medicinski fakultet, Niš, Srbija

Ovaj rad se bavi proučavanjem međusobne interakcije kvercetina i benzofenona u metanolu pod dejstvom kontinualnog UV-B ozračivanja. Praćenjem UV-B indukovanih promena HPLC hromatografijom uočeno je značajno ubrzanje degradacije kvercetina u prisustvu benzofenona. Nedvosmislenu identifikaciju degradacionih produkata kvercetina je omogućila FI-ESI-MS analiza. Prisustvo benzofenona ne samo da ubrzava već istovremeno menja mehanizam degradacije kvercetina. Ozračivanjem kvercetina u odsustvu benzofenona nastaje produkt dobijen adicijom rastvarača, 2-(3,4-dihidroksifenil)-3,5,7-trihidroksi-2,3-dimetoksi-2,3-dihidro-4H-hromen-4-on. Sa druge strane, produkti dobijeni u prisustvu benzofenona, nastali otvaranjem prstena C su identifikovani kao 3,5-dihidroksi-2-[metoksi(okso) acetil]fenil 3,4-dihidroksibenzoat i metil-okso(2,4,6-trihidroksifenil)acetat.
(ORIGINALNI NAUČNI RAD)

UDK $547.972 .3+547.572: 543.42$
Ključne reči: Kvercetin, Benzofenon, UV-B ozračivanje, HPLC, FI-ESI-MS 